\title{
A comparison of the characteristics of \\ childless women and mothers in the ONS Longitudinal Study
}

Martina Portanti and Simon Whitworth

Office for National Statistics

An increase in the number of childless women has been a prominent feature of the post baby boom period of fertility decline. However, childlessness as a stand alone research topic has received less attention within the literature on low fertility.

This research uses for the first time the ONS Longitudinal Study (LS) to explore lifelong childlessness as a research topic in its own right. Using a large scale sample of women from the 1956-60 generation who are continuously resident in England and Wales during their childbearing years, this article investigates the degree to which socio-economic characteristics of women and, where present, their partners are related to female lifelong childlessness.

The study measures the extent to which women who remained childless throughout their life course are distinctive from those who became mothers, and therefore improves our understanding of childlessness among women in England and Wales.

\section{Introduction}

Since the post Second World War baby boom there has been a dramatic change in childbearing patterns throughout the developed world (Sobotka, 2004). In general, women in most countries have been delaying starting a family, with births to women aged below 30 declining sharply over this period. Women have been having fewer children on average, and increasing numbers of women have been remaining childless. This has resulted in the fertility rate decline observed in the Western world, where many countries are now experiencing low and very low fertility rates.

The drivers of fertility decline - including childbearing postponement, decreasing family size and childlessness - have been extensively analysed in the demographic and sociological literature (for example, McDonald, 2000; Castles, 2003; Jefferies, 2008).

Childlessness, in particular, is not a new phenomenon. Hakim (2003) reported that in the past 20 per cent of women in the UK remained childless due to poverty, poor nutrition and low marriage rates caused by wars and emigration. However, in the post Second World War period, childlessness reached an all time low in Britain (Coleman, 1996). Since then, the proportion of women childless in England and Wales has been increasing, from an estimated 10 per cent of the 1945 cohort to 19 per cent of women born in 1960 (ONS, Birth Statistics, 2008). Importantly, some studies have identified present-day childlessness as being different from childlessness in the past. This is because present-day childlessness is occurring increasingly often among healthy females who are living within marriage or cohabiting and who are sexually active (Coleman, 1996).

Compared to studies of low fertility, childlessness as a stand alone research topic has received less attention within the literature (Hakim, 
2005), with most studies of childlessness being based on small-scale samples and relying heavily on qualitative methods. Some of this research in Canada (Veevers, 1980) and the UK (McAllister and Clarke, 1998) reported that childless women are not from a distinct social or economic group relative to women with children. Instead, they suggest that those who are voluntarily childless are more distinct in terms of their attitudes and values, and are characterised by a desire for independence, freedom and spontaneity (Fisher, 1991; Lisle, 1996; McAllister and Clarke, 1998).

Although some studies have looked at childlessnes in the British Household Panel Survey (Berrington, 2004) and the General Household Survey (Murphy, 2008), quantitative research on childlessness in the UK has mainly made use of data from the Birth Cohort Studies (Kiernan, 1989; Hakim, 2003; Simpson, 2006; Kneale and Joshi, 2008). For instance, Kiernan (1989) used the 1946 British Cohort Study to analyse childlessness among respondents aged 36 years old. This research found that there was no strong association between childlessness and education, and childlessness and occupation. However women who were childless were said to be distinctive from those with children in that they made a lifestyle choice that valued career and leisure activities over having children. Hakim (2003) used data from Family and Fertility Surveys (FFS) in European countries, the 1958 National Child Development Study (NCDS) and the 1970 British Cohort Study (BCS) in Great Britain to investigate the characteristics of childless people across Europe. This study found that the childless were a distinct group in terms of their attitudes and values rather than their socio-economic characteristics, when compared with those with children.

This article uses for the first time an alternative data source, the ONS Longitudinal Study (LS), to explore lifelong childlessness as a research topic in its own right ${ }^{1}$. The LS is a sample of approximately 1 per cent of the population of England and Wales and provides a large, nationally representative data source. Data from the LS have been analysed using univariate and multivariate modelling techniques to assess the social, geographical and household characteristics of women who remain childless throughout their life.

\section{Data source}

The LS is a dataset of linked census and vital events records for 1 per cent of the population of England and Wales. It includes linked individual records from the 1971, 1981, 1991 and 2001 censuses, together with routine events registrations such as births, deaths and cancer registrations. As it is a linkage study of administrative records, it is not affected by attrition due to non-response or by respondents' memory bias, which survey data may be.

The sample was initiated at the time of the 1971 Census, when all people born on four selected dates in any calendar year were included in the sample. The four dates were used again to update the sample in 1981, 1991 and 2001 and also to add new members between censuses. New members enter the study through birth and immigration and existing members leave through death and emigration. Over more than thirty years of the study, data on approximately 1 million individuals have been collected. This means that the LS has a far larger sample size than any other longitudinal study in England and Wales, thus allowing for more robust statistical inference.

The LS also includes census information for people who are enumerated in the same household as the LS member. This provides the opportunity to investigate the family contexts in which specific fertility behaviours occur. However, the information on people enumerated at the same private address as the LS member is not linked through time, and as such it can be analysed only cross-sectionally.
The LS shares some of the limitations of the census, one of its data sources. For instance, the census information is collected only once every ten years and it mostly relates to people's circumstances at the time. In addition, the LS does not cover opinions, attitudes and intentions. Although the usefulness of fertility intentions as fertility predictors has been questioned (Berrington, 2004), this does mean that in this study it is not possible to distinguish between voluntary and involuntary childlessness ${ }^{2}$.

\section{Methods}

This article uses LS data from the 1971, 1981, 1991 and 2001 censuses to investigate the circumstances of women at different key ages and to see how these are associated with their lifelong fertility outcomes. The analysis investigates the extent to which childless women appear to be distinct from women with children in terms of several social and economic characteristics identified both in the qualitative and quantitative literature.

The relationship between socio-economic circumstances and fertility behaviours may be quite complex. For example, childbearing may lead some women to leave the labour force, thus showing how parenthood may impact on employment patterns. At the same time, however, employment may impact on parenthood. For instance, several empirical studies have found that an increase in women's wages is associated with first birth postponement (De Cooman et al 1987, Joshi 2002).

It is beyond the scope of this analysis to investigate cause-effect relationships between the study variables. We concentrate instead on identifying and measuring the association between women's characteristics and childlessness, without debating the direction of this association.

Also, it should be noted that women's fertility outcomes are considered here only from a lifelong perspective. This means that women belong to only one of the two categories, 'childless' or 'mothers', depending on whether they had experienced a live- or stillbirth during their childbearing years by December 2005, and they do not move from the former to the latter group over time. When comparing the characteristics of the two groups of women, readers should also be aware that at any point in time the 'mothers' group will comprise women who are not yet mothers but who subsequently had a live- or stillbirth during their childbearing years.

This analysis compared the characteristics of women who are lifelong childless with those of mothers in order to identify statistically significant differences between the two groups. Following this univariate analysis, multivariate modelling techniques (logistic regression and log-linear models) were applied to identify the key variables that differentiated childless women from mothers.

The analysis was conducted initially on the entire sample of women. Further analysis was then performed on the subgroup of women for whom childlessness occurs within marriage or cohabitation.

\section{Prevalence of childlessness}

The sample consists of 12,578 LS female members born in the years 1956-1960 and continuously resident in England and Wales during their entire childbearing age-span; conventionally considered to be between 15 and 45 years old. As only births registered in England and Wales are linked to LS mothers, continuous residence in either of the two countries is required to ensure that fertility outcomes are correctly assigned to each woman. The sample therefore excludes women who entered the country after the age of 15 , those who left it before the age of 45 , as well as any other woman temporarily absent from England and Wales between these 

by birth cohort ${ }^{4}$

\begin{tabular}{l|c|c}
\hline \multirow{2}{*}{ Cohort } & \multicolumn{2}{|c}{ Percentage of childless women } \\
\cline { 2 - 3 } & LS & England and Wales \\
\hline 1956 & 16.5 & 16.0 \\
1957 & 17.0 & 17.0 \\
1958 & 18.0 & 18.0 \\
1959 & 17.9 & 18.0 \\
1960 & 17.8 & 18.0 \\
\hline
\end{tabular}

Source: ONS Longitudinal Study, FM1 Births Statistics, authors' analysis

two ages, as indicated by their absence at one of the censuses. Also, all women who died before 45 years of age have been excluded from the sample.

A woman is here defined as being childless if she had not had any liveor stillbirth by December 2005. Childlessness is therefore defined from a biological perspective, although a childless woman may actually have acted as a mother to children that she did not bear herself (for example, foster and adoptive parents and women looking after their partner's children). Similarly, a biological mother may not be acting as such from a social perspective (for example, a mother whose child has been adopted by other parents). However, for simplicity of expression, we will from here on refer to the first group as 'childless' and to the second as 'mothers'.

Table 1 compares the percentages of childless women in the LS with published 2005 Birth Statistics for England and Wales ${ }^{3}$ (ONS, 2006). Overall, 2,194 LS women from the 1956-1960 cohorts had not given birth by the end of 2005 . This is around 17 per cent of the sample and is consistent with national estimates. The LS can therefore be considered to be a reliable and representative sample of childless females in England and Wales as a whole.

\section{Characteristics of childless women and mothers}

Information on individuals' characteristics including, among others, marital/partnership status, education, economic activity and social class is available in the LS for each census from 1971. This allows investigation of the extent to which sample women who are lifelong childless differ from the mothers group not only at the end of their childbearing age but also throughout their child- and adulthood.

\section{Marital status and partnerships}

The LS contains information about the marital status of its members at each census. Table 2 shows the marital status of the women in the sample in 2001, when they were between 41 and 45 years old, thus approaching the end of their childbearing years.
Childless women and mothers in 2005: percentage distribution by marital status in 2001

\begin{tabular}{lcc|c}
\hline Marital status & Childless & Mothers & All \\
\hline Single (never married)* & 40.2 & 5.3 & 11.4 \\
Married (first marriage)* $^{*}$ & 35.3 & 59.9 & 55.6 \\
Re-married* $^{*}$ & 8.9 & 12.8 & 12.1 \\
Separated but still legally married* $^{*}$ & 2.2 & 4.6 & 4.2 \\
Divorced* $_{\text {Widowed }}$ & 12.6 & 16.3 & 15.6 \\
Total & 0.7 & 1.1 & 1.1 \\
& 100 & 100 & 100
\end{tabular}

* Difference between childless women and mothers statistically significant at the 0.05 level. Source: ONS Longitudinal Study, authors' analysis

Unsurprisingly, compared to the mothers group, childless women are more often single, with 40.2 per cent never having been married. The remaining majority (59.8 per cent), however, had experienced marriage during their lives. Indeed, around 44.2 per cent of childless women were recorded as married in the 2001 Census ( 35.3 per cent in a first marriage and 8.9 per cent in a successive marriage). An additional 15.5 per cent, although not married in 2001, had been married previously and then been separated ( 2.2 per cent), divorced (12.6 per cent) or widowed ( 0.7 per cent).

Apart from differences in the levels of legal unions, differences in their timing exist between the two groups of women. Marital status distributions at the 1981, 1991 and 2001 censuses (see Table 3), show that while the proportion of childless women in a marriage of any order is at its highest in 2001, at 44.2 per cent, the peak in marriages among the women with children is reached in 1991 , when 80.2 per cent of this group of women were recorded as married.

Marital status information provides only a partial picture of partnerships, as it does not capture cohabitations. As the LS includes information on those individuals enumerated in the same household as the LS member, it is possible to identify those women cohabiting with a partner, irrespective of their legal marital status. Table 3 shows the percentages of childless women and mothers who were married or cohabiting at specified ages. These percentages are also reported in the brackets as proportions of all unions in each group of women. In 2001, 12.5 per cent of childless women were cohabiting, thus raising the percentage in a partnership to 56.7 per cent. Cohabitation is relatively more common among childless women than among mothers. The gap between the two groups of women is widest in their early thirties, when 23 per cent of childless women were cohabiting compared to only 7.9 per cent for women with children.

Finally, information on presence of a partner at each of the 1981, 1991 and 2001 censuses was combined to derive a summary indicator for partnerships over women's entire childbearing periods (Table 4).

\begin{tabular}{|c|c|c|c|c|c|c|}
\hline & \multicolumn{2}{|c|}{$\begin{array}{c}1981 \\
\text { Age } 20-25\end{array}$} & \multicolumn{2}{|c|}{$\begin{array}{c}1991 \\
\text { Age } 30-35\end{array}$} & \multicolumn{2}{|c|}{$\begin{array}{c}2001 \\
\text { Age } 40-45\end{array}$} \\
\hline & Childless & Mothers & Childless & Mothers & Childless & Mothers \\
\hline Married (any order) & $21.1(85.8)$ & $54.2(92.5)$ & $40.8(77.0)$ & $80.2(92.1)$ & $44.2(78.0)$ & $72.7(89.8)$ \\
\hline Cohabiting & $3.5(14.2)$ & $4.4(7.5)$ & $12.2(23.0)$ & $6.9(7.9)$ & $12.5(22.0)$ & $8.3(10.2)$ \\
\hline All unions & $24.6(100)$ & $58.6(100)$ & $53.0(100)$ & $87.1(100)$ & $56.7(100)$ & $81.0(100)$ \\
\hline
\end{tabular}

Note: Figures in brackets represent the percentage of childless women/mothers who were married or cohabiting (cell percentage) as a percentage of all childless women/mothers in a union (column total percentage).

Source: ONS Longitudinal Study, authors' analysis 
Childless women and mothers in 2005: percentage distribution by presence of partner, 1981-2001

\begin{tabular}{lcccc}
\hline & Childless & Mothers & All women \\
\hline In a partnership at each Census* & 15.7 & 42.5 & 37.9 \\
In a partnership at least at one Census* & 52.0 & 52.9 & 52.7 \\
Never in a partnership* & 32.3 & 4.6 & 9.4 \\
Total & 100 & 100 & 100 \\
\hline
\end{tabular}

* Difference between childless women and mothers statistically significant at the 0.05 level. Source: ONS Longitudinal Study, authors' analysis

\section{Table 5}

Childless women and mothers in 2005: percentage distribution by educational qualification, 2001

\begin{tabular}{lcccc}
\hline Education level & Childless & Mothers & All women \\
\hline No academic or professional qualifications* & 16.8 & 21.7 & 20.9 \\
Below degree level & 53.4 & 55.7 & 55.3 \\
$\quad$ Level 1 & 24.0 & 25.0 & 24.8 \\
Level 2 & 21.5 & 24.1 & 23.7 \\
Level 3 & 7.9 & 6.6 & 6.8 \\
Degree level and above* & 26.8 & 19.2 & 20.5 \\
Other qualifications/Level unknown & 3.0 & 3.4 & 3.3 \\
Total & 100 & 100 & 100 \\
\hline
\end{tabular}

*Difference between childless women and mothers statistically significant at the 0.05 level. Source: ONS Longitudinal Study, authors' analysis

Around 42.5 per cent of mothers were living with a partner (either being married or cohabiting) at all three censuses compared to less than 16 per cent of childless women. Also, only 4.6 per cent of mothers were never enumerated as living with a partner/husband, compared to 32.3 per cent of childless women. Although these figures confirm that not having a partner is associated with childlessness, they also indicate that the large majority of childless women, at least ${ }^{5} 68$ per cent, had been living with a partner for some time during their childbearing years ${ }^{6}$.

\section{Education}

The majority of the women in the sample had some level of educational qualification in 2001 (Table 5), with 20.5 per cent qualified to degree level or above. Although limited, some differences exist between the educational attainment of the mothers group and childless women. Compared to mothers, childless women were statistically significantly more likely to be qualified to degree level or above (26.8 per cent and 19.2 per cent respectively). Also, only 16.8 per cent of childless women did not have any qualifications, compared to 21.7 per cent of mothers.

\section{Economic activity and social class}

Levels and patterns of labour market participation by gender and age have been extensively researched and are regularly measured ${ }^{7}$. During child-rearing, women's participation in the labour market tends to decrease. In 2003, 68 per cent of women with dependent children were in the labour market compared to 76 per cent of those without children (ONS, Focus on Gender, 2004).

Figure 1 shows levels of economic activity for the sample women at three different census time points. Activity rates are shown for when the cohort is aged 20-25, 30-35 and 40-45.

Levels of economic activity differ between lifelong childless women and mothers. At any age, childless women show a higher participation in the labour market, with economic activity rates as high as 90 per cent. The age patterns of economic activity also differ between the two groups of women. Rates of participation for childless women tend to be quite

\section{Figure 1}

Childless women and mothers in 2005: economic activity rates for this cohort 1981-2001

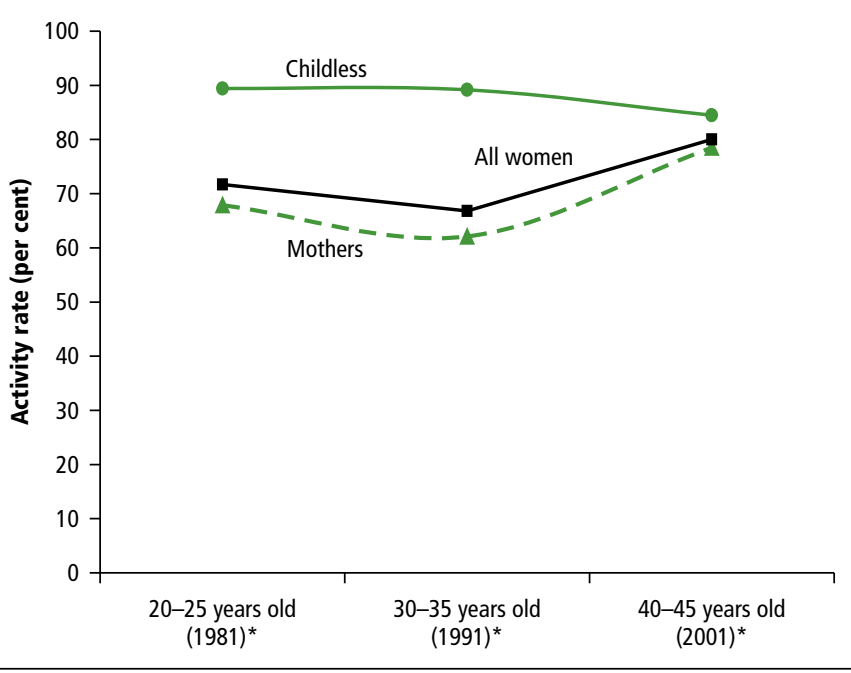

* Difference between childless women and mothers is statistically significant at the 0.05 level.

Source: ONS Longitudinal Study, authors' own analysis

constant over time, with a slight reduction only at the 2001 census, when women were aged between 40 and 45 . The lowest level of participation in the labour market is instead reached between ages 30 and 35 for mothers. Economic activity levels then recover over the following 10 years, with almost 80 per cent of women with children being economically active by 2001. At this point in time, the difference between the activity levels of childless women and mothers reduces to 6 percentage points only.

Although levels of economic activity are similar by 2001, Figure 2 indicates that the nature of participation in the labour market is quite different between the two groups.

Compared to mothers, childless women were more often employed in 'Professional' and 'Managerial/technical' occupations. In 2001, when the study cohort was aged between 40 and 45 , around 30 per cent of mothers were occupied in 'Professional and 'Managerial/technical' occupations,

Figure 2

Childless women and mothers in 2005 : percentage distribution by own social class, Registrar General Social Class classification, 2001

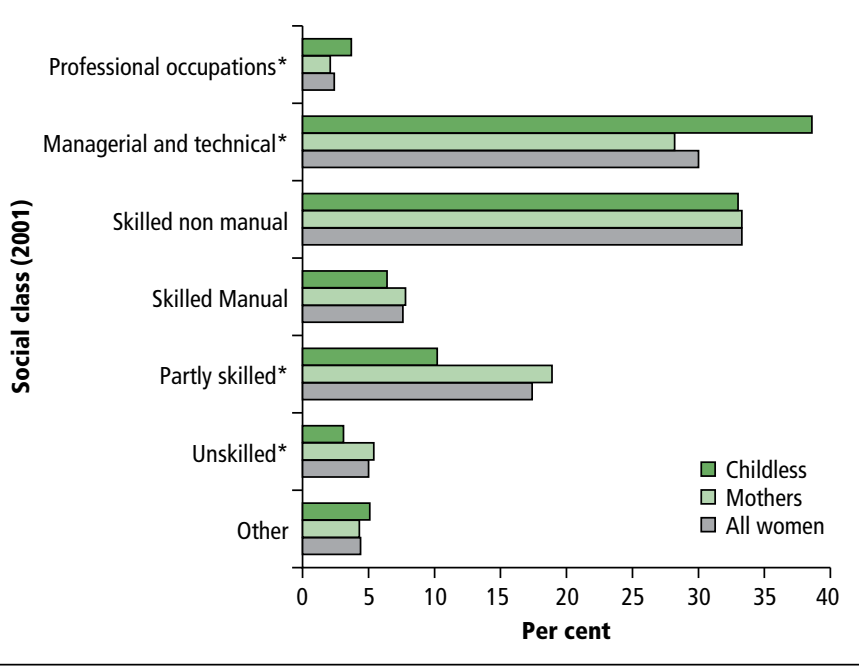

Difference between childless women and mothers is statistically significant at the 0.05 level.

Source: ONS Longitudinal Study, authors' own analysis 
Childless women and mothers in 2005: percentage distribution by housing characteristics, 2001

\begin{tabular}{lcccc}
\hline Housing characteristic & Childless & Mothers & All women \\
\hline Owned outright* $^{*}$ & 20.6 & 11.6 & 13.2 \\
Owned with mortgage $^{*}$ & 61.7 & 68.3 & 67.2 \\
Social rented* $^{*}$ & 10.1 & 14.5 & 13.4 \\
Rented from Private landlord* & 4.8 & 3.5 & 3.7 \\
Other & 2.2 & 1.6 & 2.2 \\
Total & 100 & 100 & 100 \\
\hline
\end{tabular}

* Difference between childless women and mothers statistically significant at the 0.05 level. Source: ONS Longitudinal Study, authors' analysis

compared to around 42 per cent of childless women. At the other end of the scale, around 13 per cent of childless women were in 'Partly skilled' and 'Unskilled' occupations compared to around 24 per cent of mothers.

Our findings suggest that childless women have a slightly higher social and economic status, on average, as compared to the mothers group. This is also reflected in the housing characteristics of the two groups (Table 6). Indeed, in 200120.6 per cent of childless women were living in accomodation that was owned outright by the occupier, compared to only 11.6 per cent of mothers. The latter were also more likely to rent their homes from local authorities and housing associations (social rent).

\section{Residence and geographical mobility}

Table 7 shows prevalence of childlessness by women's region of residence in 2001

In 2001, women who were childless at the end of their childbearing years were more likely than mothers to be living in London (12.2 per cent versus 8.1 per cent); mothers were more likely than childless women to be living in Wales and Yorkshire and The Humber. In the other regions, differences between childless women and mothers are not statistically significant.

As the LS contains information on place of residence at each census, it is possible to investigate not only where women were living towards the end of their childbearing age but also where they were living previously. Consequently, we can investigate whether there is any relation between migration patterns and fertility outcomes ${ }^{8}$. Tables 8 and 9 present some figures related to migration patterns in two regions at opposite ends of the childlessness spectrum: London, which had the highest relative presence of childless women; and Wales, with the lowest.

\section{Table 7}

Childless women and mothers in 2005: percentage distribution by Government Office Region (GOR) of women's residence in 2001

\begin{tabular}{l|c|c|c}
\hline Region & Childless & Mothers & All women \\
\hline North East & 5.3 & 5.5 & 5.4 \\
North West & 13.4 & 13.7 & 13.7 \\
Yorkshire and Humber* & 9.0 & 10.5 & 10.2 \\
East Midlands & 8.5 & 8.6 & 8.6 \\
West Midlands & 10.9 & 10.7 & 10.8 \\
East of England & 9.8 & 11.3 & 11.1 \\
London* & 12.2 & 8.1 & 8.8 \\
South East & 16.3 & 15.9 & 15.9 \\
South West & 9.8 & 9.8 & 9.8 \\
Wales* & 4.7 & 5.9 & 5.7 \\
Total & 100 & 100 & 100
\end{tabular}

* Difference between childless women and mothers statistically significant at the 0.05 level. Source: ONS Longitudinal Study, authors' analysis
Childless women and mothers in 2005: percentage distribution by migration patterns, women resident in London in 2001

\begin{tabular}{lcc|c}
\hline Previous residence & Childless & Mothers & All \\
\hline Always resident in the South East Standard region* & 70.8 & 83.8 & 80.7 \\
$\begin{array}{l}\text { Resident outside the South East Standard Region } \\
\text { in 1971, 1981 or 1991* }\end{array}$ & 29.2 & 16.2 & 19.3 \\
All London residents & 100 & 100 & 100
\end{tabular}

Difference between childless women and mothers statistically significant at the 0.05 level. Source: ONS Longitudinal Study, authors' analysis

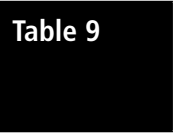

Childless women and mothers in 2005: percentage distribution by migration patterns, women resident in Wales in 2001

\begin{tabular}{lcc|c}
\hline Previous residence & Childless & Mothers & All women \\
\hline Always resident in Wales & 74.0 & 80.6 & 79.7 \\
Resident outside Wales in 1971, 1981 or 1991 & 26.0 & 19.4 & 20.3 \\
All Wales residents & 100 & 100 & 100
\end{tabular}

* Difference between childless women and mothers statistically significant at the 0.05 level Source: ONS Longitudinal Study, authors' analysis

Geographical analysis using the LS is complicated by changes in the geographical classifications over time. In particular, up to and including the 1991 Census, the Statistical Standard Region (SSR) classification was used while in the 2001 Census the Government Office Region (GOR) classification was introduced. Notably, among other changes, London became a stand-alone GOR region, while previously it was included in the South East SSR.

Almost 30 per cent of childless women resident in London in 2001 had lived outside the SSR either in 1971, 1981 or 1991. In contrast, only 16 per cent of mothers resident in London in 2001 had been previously resident outside the South East. A similar trend, although in this case not statistically significant, can be found for women living in Wales in 2001, where 26 per cent of childless women were in-migrants compared to only 19.4 per cent of mothers. Therefore, this evidence suggests that long distance migration appears to be negatively associated with motherhood.

\section{Ethnicity}

Table 10 shows the ethnic groups of childless women and mothers who have been resident in the UK since 1971. The ethnic composition of the childless and the mothers groups are very similar, with the only difference being a significantly higher presence of Asian women among the mothers. However, inferences about the association between childlessness and ethnicity based on this sample should be treated with caution. This is because only 3 per cent of the women in the sample

Table 10

Childless women and mothers in 2005: percentage distribution by ethnic group, 2001

\begin{tabular}{l|c|c|c}
\hline Main ethnic group & Childless & Mothers & All women \\
\hline White & 97.9 & 97.2 & 100 \\
Mixed & 0.6 & 0.4 & 100 \\
Asian* & 0.6 & 1.2 & 100 \\
Black & 0.6 & 0.9 & 100 \\
Chinese & 0.1 & 0.1 & 100 \\
All women & 100 & 100 & 100
\end{tabular}

* Difference between childless women and mothers statistically significant at the 0.05 level. Source: ONS Longitudinal Study, authors' analysis 
belonged to a 'non-white' ethnic group 9 . The small sample size limits the scope of the statistical analysis that can be conducted on the relationship between ethnicity and childbearing outcomes in the sample.

\section{Early life course variables}

Variables whose values are typically determined either at birth or during a person's childhood are known as early lifecourse variables. These have been shown to have significant predictive power for identifying which women will be childless in later life (Parr 2005). We have used the LS to investigate the association between motherhood/childlessness and the household and family context in which women lived during their own childhood.

Table 11 indicates that in 1971 when the cohort was aged between 10 and 15 , significantly more childless women than mothers had no siblings in their household. This pattern is consistent with that identified by Kiernan (1989) who found that among British women aged 36 years, those who were only children had the highest rate of childlessness.

A relationship also emerges between the socio-economic background of the women in the sample and their later life fertility outcome. Socio-economic background is measured by the social class of the Main Economic Supporter (MES) of the women's family when they were aged between 10 and 15, in 1971. Women whose MES was in a higher social class (for example, Professional, Managerial and Non-manual occupations) tended to be more often childless than women whose MES was in a manual occupation (Table 12). However, differences are not statistically significant for all social classes and overall the gradient is not as strong as that associated with the woman's own social class.

\section{Limiting long-term illness}

In 2001 and 1991 the census included a question on health, asking all respondents whether they had any long-term illness, health problem or disability which limited their daily activities or the work that they could do. In the absence of more detailed information, this can be used

\section{Table 11 \\ Childless women and mothers in 2005: percentage distribution by presence of sibling in the household in 1971}

\begin{tabular}{l|c|c|c}
\hline Presence of sibling (1971) & Childless & Mothers & All women \\
\hline No sibling present* & 14.9 & 11.4 & 12.0 \\
Sibling present* & 85.1 & 88.6 & 88.0 \\
Total & 100 & 100 & 100
\end{tabular}

* Difference between childless women and mothers statistically significant at the 0.05 level. Source: ONS Longitudinal Study, authors' analysis

\section{Table 12}

Childless women and mothers in 2005: percentage distribution by social class of LS member's Main Economic Supporter in 1971

\begin{tabular}{lcccc}
\hline Social class of MES & Childless & Mothers & All women \\
\hline Professional occupations & 5.8 & 4.9 & 5.1 \\
Managerial and technical* $^{*}$ & 21.2 & 17.1 & 17.8 \\
Skilled non manual $^{*}$ & 10.9 & 10.3 & 10.4 \\
Skilled manual* $^{*}$ & 37.2 & 40.0 & 39.6 \\
Partly skilled* $^{*}$ & 15.3 & 17.2 & 16.9 \\
Unskilled $_{\text {Other }}$ & 5.2 & 6.2 & 6.0 \\
Total & 4.4 & 4.2 & 4.3 \\
\end{tabular}

* Difference between childless women and mothers statistically significant at the 0.05 level. Source: ONS Longitudinal Study, authors' analysis
Childless women and mothers in 2005: percentage distribution by Limiting Long Term Illness in 2001

\begin{tabular}{lcccc}
\hline Health & Childless & Mothers & All women \\
\hline Has a limiting long term illness* & 17.1 & 11.7 & 12.7 \\
Does not have a limiting long term illness* & 82.9 & 88.3 & 87.3 \\
Total & 100 & 100 & 100
\end{tabular}

Difference between childless women and mothers statistically significant at the 0.05 level. Source: ONS Longitudinal Study, authors' analysis

as a proxy for the health status of respondents. As shown in Table 13 in 2001, a higher proportion of childless women (17.1 per cent) than women with children (11.7 per cent) had a limiting long-term illness. These figures suggest a relationship between women's health and their fertility outcomes, although the data available in the LS does not allow investigation of its direction.

\section{Logistic regression}

The univariate analysis presented so far does not allow the identification and measurement of the interrelationship between the different variables associated with childlessness. For example, the observed association between the social class of a woman's family of origin and her being childless may actually be a spurious relationship. In fact, her family's social class may actually be associated only (or mainly) with her own social class and this may be one factor directly related to her fertility outcome. Similarly, the effect of education on fertility outcomes may be mediated by economic activity and social class and so on. In order to identify the net effects of each variable on childlessness it is necessary to use multivariate modelling techniques.

Logistic regression was used to model the probability of lifetime childlessness based on a number of women's individual characteristics.

Those variables analysed at the univariate level were entered in the regression and retained when their contribution to the model was statistically significant at the 0.05 level. A new variable, living arrangement, was created by combining information on legal marital status and presence of a partner in the LS member's household.

The model's coefficients are reported in Table 14. A positive value for a beta coefficient, or alternatively a value greater than 1 for the odds ratio, indicates that the variable/category has a positive association with being childless and negative otherwise. Categories in italics are not statistically significant at the 0.05 level.

Regression results confirmed some of the results of the univariate analysis while allowing for a better understanding of some of the relationships between the different variables.

Living arrangements are, as expected, strongly associated with childlessness (rows 1-15, Table 14). Women who are single, in the sense of never married, are consistently more likely to be lifetime childless, even when cohabiting with a partner (rows $2-3,7-8,12-13$, Table 14). Also women who had experienced the dissolution of a marriage (divorced or widowed) are less likely to become mothers, even if remarried (rows 14-15, Table 14).

Living arrangements at different ages impact differently on lifetime childlessness. Women who were cohabiting with a partner in their early thirties are more likely to be lifetime childless than those who were cohabiting at any other age.

Economic activity coefficients reflect the relationships identified in the previous descriptive analysis, with participation in the labour market 
Table 14 Logistic regression model for probability of lifetime childlessness, all women

\begin{tabular}{|c|c|c|c|c|}
\hline ID & Variable & $\begin{array}{c}\text { Beta } \\
\text { coefficient }\end{array}$ & $\begin{array}{l}\text { Standard } \\
\text { error }\end{array}$ & $\begin{array}{l}\text { Odds } \\
\text { ratio }\end{array}$ \\
\hline 1 & $\begin{array}{l}\text { Living arrangements } 1981 \\
\text { Baseline: Married }\end{array}$ & & & \\
\hline 2 & Single & 0.88 & 0.07 & 2.42 \\
\hline 3 & Single but living with a partner & 0.38 & 0.16 & 1.46 \\
\hline 4 & Re-married & 0.44 & 0.32 & 1.55 \\
\hline 5 & Divorced, widowed & 0.04 & 0.23 & 1.04 \\
\hline 6 & $\begin{array}{l}\text { Living arrangements } 1991 \\
\text { Baseline: married }\end{array}$ & & & \\
\hline 7 & Single & 1.25 & 0.11 & 3.49 \\
\hline 8 & Single but living with a partner & 0.80 & 0.12 & 2.23 \\
\hline 9 & Re-married & 0.17 & 0.15 & 1.19 \\
\hline 10 & Divorced, widowed & 0.52 & 0.11 & 1.69 \\
\hline 11 & $\begin{array}{l}\text { Living arrangements } 2001 \\
\text { Baseline: married }\end{array}$ & & & \\
\hline 12 & Single & 1.61 & 0.12 & 5.00 \\
\hline 13 & Single but living with a partner & 0.60 & 0.14 & 1.81 \\
\hline 14 & Re-married & 0.26 & 0.12 & 1.30 \\
\hline 15 & Divorced, widowed & 0.29 & 0.09 & 1.33 \\
\hline 16 & $\begin{array}{l}\text { Economic activity } 1991 \\
\text { Baseline: Economic Inactive }\end{array}$ & & & \\
\hline 17 & Unemployed & 1.71 & 0.16 & 5.52 \\
\hline 18 & Self-employed & 1.22 & 0.17 & 3.37 \\
\hline 19 & Employed & 1.72 & 0.10 & 5.58 \\
\hline 20 & Economic Activity 2001 & & & \\
\hline 21 & Unemployed & 0.69 & 0.2 & 1.99 \\
\hline 22 & Self-employed & 0.40 & 0.14 & 1.49 \\
\hline 23 & Employed & 0.55 & 0.09 & 1.73 \\
\hline 24 & $\begin{array}{l}\text { Social Class } 1991 \\
\text { Baseline - Unskilled }\end{array}$ & & & \\
\hline 25 & I-Professional & 1.38 & 0.25 & 3.97 \\
\hline 26 & II - Intermediate & 1.32 & 0.19 & 3.75 \\
\hline 27 & IIIN - Skilled Non Manual & 1.15 & 0.18 & 3.16 \\
\hline 28 & IIIM - Skilled Manual & 1.18 & 0.21 & 3.25 \\
\hline 29 & IV - Partly Skilled & 0.61 & 0.20 & 1.84 \\
\hline 30 & Other & 0.76 & 0.22 & 2.13 \\
\hline 31 & $\begin{array}{l}\text { Ethnicity } 2001 \\
\text { Baseline: White }\end{array}$ & & & \\
\hline 32 & Mixed & 0.06 & 0.40 & 1.07 \\
\hline 33 & Asian & -0.63 & 0.41 & 0.53 \\
\hline 34 & Black & -1.81 & 0.35 & 0.16 \\
\hline 35 & Chinese & 0.37 & 0.95 & 1.45 \\
\hline 36 & Has a Limiting Long Term Illness 1991 & 1.46 & 0.13 & 4.31 \\
\hline 37 & Has a Limiting Long Term Illness 2001 & 0.55 & 0.09 & 1.74 \\
\hline 38 & Does not have siblings 1971 & 0.33 & 0.08 & 1.40 \\
\hline 39 & Constant & -5.78 & 0.22 & 0 \\
\hline
\end{tabular}

Italic lines indicate non-significant coefficients at the 0.05 level.

Source: ONS Longitudinal Study, Authors' analysis

being associated with childlessness. The higher coefficients observed in 1991 compared with 2001 are a reflection of mothers returning to work after childbearing and child-rearing (see rows 16-23 in Table 14). The 1991 social class gradient is confirmed, too, showing how women from higher social classes are more likely to be childless (see rows 24-30, Table 14). However, the variable social class in 1981 and 2001 was not statistically significant once social class in 1991 was taken into account. This is likely to be explained by the fact that the majority of individuals experience only limited social class mobility over time. This means that the social class variables are highly correlated over time.

The relationship between health and childlessness is also confirmed, with childless women relatively more likely to have a limiting long-term illness (rows $36-37$, Table 14). This association is particularly strong for
1991, when the sample group were in their early thirties, the middle of their reproductive timespan.

Once social class is taken into account, many of the ethnic differences in fertility outcomes disappear (rows 31-35, Table 14). Black women are the only group to appear significantly less likely to be childless when compared to the White reference group.

The relationship between family background and childlessness, which was identified earlier, is reduced to some extent after controlling for other variables (row 38, Table 14). Although not having siblings still appears to increase the likelihood of being childless later in life, the association between the family-of-origin's social class and childlessness disappears.

Finally, geographical residence and mobility are excluded from the model as they are not statistically significant. This suggests that most of the differences in fertility outcomes between different regions of England and Wales are related to geographical differentials in economic activity, social class and partnership formation and dissolution.

\section{Characteristics of women's partners}

Individual characteristics of women play an important role in whether or not they remain childless. For example, the single highest coefficient in the model described in section 5.8 was the women's economic activity variable in 1991 (row 19 in Table 14). The analysis has also shown that one of the main factors associated with childlessness is the lack of a partner. For instance, the odds of being childless for never married women not living with a partner at the 2001 Census point are five times those of women who were married at that census. However, various studies have pointed out that present-day childlessness is occurring more frequently within marriage and cohabitation (Coleman, 1996; Hakim, 2005). The analysis in section 5.1 also stated that at least 68 per cent of childless women had cohabited with a partner at some time during their childbearing years.

We therefore focused on investigating childlessness among the subgroup of women who were married or cohabiting. In particular, we were interested in measuring the extent to which the partners of childless women were distinctive from the partners of those who had become mothers by 2005 . This allowed us to measure the impact of a partner's characteristics on a woman's fertility outcomes.

We analysed women in a partnership in 1991, when they were in their early- to mid- thirties. In the LS, partners are not linked through time so only cross-sectional analysis is possible here ${ }^{10}$. The 1991 Census was chosen for several reasons. Firstly, results from the previous logistic regression analysis suggested that women's socio-economic circumstances in 1991 were more strongly linked with their fertility outcomes than their circumstances in 1981. Secondly, log-linear models were used to measure the association between having a partner at each of the three censuses and being childless (see Table A1 in the Appendix) and this analysis showed that not having a partner in 1981 or 1991 had a stronger effect on childlessness than not having a partner in 2001. Finally, more women were enumerated as living with a partner in $1991(9,786)$ compared with $1981(6,154)$ and $2001(9,345)$ and, as such, we were able to analyse a larger sample of partners in 1991. Around 50 per cent of the childless group (1,101 women) and 84 per cent of the mother group (8,685 women) had a partner in 1991.

\section{Marital status}

Marital status data for both women and their partners can be used to explore in more detail the characteristics of these unions (Table 15). Couples in a traditional first marriage (for both partners) accounted for around 74 per cent of the mothers group but only 53 per cent of the childless group. Childless women and their partners were also more 
Table 15

Childless women and mothers in 2005: percentage distribution by marital status of couples, 1991

\begin{tabular}{l|l|c|c|c}
\hline Woman & Partner & Childless & Mothers & All women \\
\hline 1 Married* $^{*}$ Married & 52.6 & 73.9 & 71.5 \\
2 Married* $^{*}$ & Re-married & 12.8 & 7.4 & 8.0 \\
3 Single* & Single & 10.9 & 2.8 & 3.7 \\
4 Single * & Divorced & 5.7 & 1.2 & 1.7 \\
5 Re-married & Married & 4.5 & 5.8 & 5.7 \\
6 Re-married & Re-married & 4.9 & 4.1 & 4.2 \\
7 Divorced & Single & 2.2 & 1.7 & 1.7 \\
8 Divorced & Divorced & 2.5 & 1.9 & 1.9 \\
9 Other & & 3.9 & 1.2 & 1.6 \\
10 All couples & & 100 & 100 & 100 \\
\hline
\end{tabular}

* Difference between childless women and mothers statistically significant at the 0.05 level. Source: ONS Longitudinal Study, authors' analysis

often single (that is, never married) than the mothers and their partners

(11 per cent and 3 per cent respectively).

Around 25.9 per cent of childless women were either in a marital (including remarried) or cohabiting relationship with a partner who had experienced a previous relationship-breakdown and was now remarried or still divorced (rows 2, 4, 6, 8, Table 15). For women with children this figure is only 14.6 per cent.

\section{Age}

Some qualitative research has suggested that in the childless group, women tend more often to have older partners, sometimes up to ten years older (McAllister and Clarke, 1998). Our analysis confirmed this result, as shown in Table 16. Around 37.3 per cent of mothers, but only 27.8 per cent of childless women, were approximately the same age as their partners; that is, they are up to one year younger or older than their partners. Compared to the mothers group, significantly wider age gaps existed between childless women and their partners. Indeed, around 27.4 per cent of childless women had partners who were more than five years older than them. This was the case for only 16.3 per cent of mothers. Childless women also had younger partners, with 4.8 per cent having a partner who was more than five years younger than them, compared with 2.7 per cent of mothers.

\section{Education and social class}

Some authors suggest that childlessness is more common among couples who have very similar educational and occupational levels, and thus there is little or no differentiation of roles, interests and activities within their relationship (for example, Hakim, 2003). We therefore tested the association between childlessness and educational/occupational homogamy in our sample.

\section{Table 16}

Childless women and mothers in 2005: percentage distribution by age gap between partners, 1991

\begin{tabular}{lcccc}
\hline Age gap & Childless & Mothers & All women \\
\hline Woman's partner more than 5 years younger* & 4.8 & 2.7 & 3.0 \\
Woman's partner between 5 and 2 years younger & 13.4 & 12.3 & 12.4 \\
Woman's partner between one year younger and & 27.8 & 37.3 & 36.2 \\
1 year older* & & & \\
Woman's partner between 2 and 5 years older* & 26.6 & 31.4 & 30.9 \\
Woman's partner between 6 and 10 years older* & 16.6 & 12.0 & 12.5 \\
Woman's partner more than 10 years older* & 10.8 & 4.3 & 5.1 \\
All couples & 100 & 100 & 100
\end{tabular}

* Difference between childless women and mothers statistically significant at the 0.05 level. Source: ONS Longitudinal Study, authors' analysis
Table 17

Childless women and mothers in 2005: percentage distribution by couples' educational attainment, 1991

\begin{tabular}{llcccc}
\hline Woman & Partner & Childless & Mothers & All women \\
\hline Degree* & Degree & 7.2 & 5.0 & 5.2 \\
Degree & Sub-degree & 1.3 & 0.8 & 0.8 \\
Degree* & No qualification & 4.7 & 2.1 & 2.4 \\
Sub-degree & Sub-degree & 1.6 & 1.2 & 1.2 \\
Sub-degree & Degree & 1.9 & 2.2 & 2.1 \\
Sub-degree* & No qualification & 6.8 & 5.2 & 5.4 \\
No qualification & Degree & 4.7 & 5.1 & 5.1 \\
No qualification & Sub-degree & 5.8 & 5.1 & 5.2 \\
No qualification* & No-qualification & 65.9 & 73.3 & 72.5 \\
Woman more educated than partner & & 12.8 & 8.1 & 8.6 \\
Same educational level & & 74.7 & 79.5 & 79 \\
Same educational level & & 8.8 & 6.2 & 6.4 \\
(excluding no qualifications) & & 12.4 & 12.4 & 12.4 \\
Woman less educated than partner & & 100 & 100 & 100 \\
All couples & & & & \\
\hline
\end{tabular}

* Difference between childless women and mothers statistically significant at the 0.05 level. Source: ONS Longitudinal Study, authors' analysis

Analysis of educational homogamy was limited by the small amount of detail on educational qualifications collected at the time of the 1991 Census ${ }^{11}$. The education variable available within the LS makes a distinction between only three levels of education: individuals with a degree (or higher), individuals with some qualification attained after age 18 but lower than a degree, and people without any educational qualification attained after age 18 .

Childlessness appears more frequent when women are more highly educated than their partners. Almost 13 per cent of childless women were better educated than their partners, compared to only around 8 per cent of mothers (Table 17). We found limited evidence to support the hypothesis that educational homogamy is associated with childlessness. Childless women actually present lower levels of educational homogamy compared with the mothers ( 74.7 per cent versus 79.5 per cent). However, this result was largely driven by couples where both partners had not attained any qualification after age 18. The 'No qualification' group is itself extremely heterogeneous, comprising both people who left school with and without educational qualifications. Where both partners have 'No qualifications' after age 18 they may in fact have different educational levels and, as such, it is more appropriate to exclude them from the 'Same educational level' category. By doing so, couples with the same educational level are, indeed, more common among childless women ( 8.8 per cent) than among mothers (6.2 per cent).

In addition, there is evidence of an association between occupational homogamy and childlessness (Table 18). Statistically significantly more childless women belonged to the same social class as their partner

Table 18

Childless women and mothers in 2005: percentage distribution by couples' social class, 1991

\begin{tabular}{lcccc}
\hline & Childless & Mothers & All women \\
\hline Same social class* & 30.5 & 25.2 & 25.8 \\
Partner lower social class* & 39.0 & 34.1 & 34.7 \\
Partner higher social class & 30.6 & 40.8 & 39.5 \\
Total & 100 & 100 & 100
\end{tabular}

Difference between childless women and mothers statistically significant at the 0.05 level. Source: ONS Longitudinal Study, authors' analysis 
Table 19 Logistic regression model for probability of lifetime childlessness, women with a partner 1991

\begin{tabular}{|c|c|c|c|c|}
\hline ID & Variable & $\begin{array}{c}\text { Beta } \\
\text { coefficient }\end{array}$ & $\begin{array}{l}\text { Standard } \\
\text { error }\end{array}$ & Odds ratio \\
\hline 1 & $\begin{array}{l}\text { Age gap between partners } \\
\text { Baseline: Woman's partner between one year } \\
\text { younger and } 1 \text { year older }\end{array}$ & & & \\
\hline 2 & Woman's partner more than 5 years younger & 0.431 & 0.190 & 1.54 \\
\hline 3 & $\begin{array}{l}\text { Woman's partner between } 5 \text { and } 2 \text { years } \\
\text { younger }\end{array}$ & 0.097 & 0.117 & 1.10 \\
\hline 4 & Woman's partner between 2 and 5 years older & 0.159 & 0.091 & 1.17 \\
\hline 5 & $\begin{array}{l}\text { Woman's partner between } 6 \text { and } 10 \text { years } \\
\text { older }\end{array}$ & 0.524 & 0.116 & 1.69 \\
\hline 6 & Woman's partner more than 10 years older & 0.856 & 0.154 & 2.35 \\
\hline 7 & $\begin{array}{l}\text { Living arrangements } 1991 \\
\text { Baseline: LS member and partner in their first } \\
\text { marriage }\end{array}$ & & & \\
\hline 8 & LS member married, partner re-married & 0.400 & 0.123 & 1.49 \\
\hline 9 & LS member single, partner single & 0.822 & 0.170 & 2.28 \\
\hline 10 & LS member single, partner divorced/widower & 1.031 & 0.203 & 2.80 \\
\hline 11 & LS member remarried, partner married & 0.232 & 0.199 & 1.26 \\
\hline 12 & LS member remarried, partner remarried & 0.376 & 0.203 & 1.46 \\
\hline 13 & LS member divorced/widow, partner single & 0.623 & 0.256 & 1.86 \\
\hline 14 & $\begin{array}{l}\text { LS member divorced/widow, partner } \\
\text { divorced/widower }\end{array}$ & 0.529 & 0.229 & 1.70 \\
\hline 15 & $\begin{array}{l}\text { Living arrangements } 1981 \\
\text { Baseline: married }\end{array}$ & & & \\
\hline 16 & Single & 0.805 & 0.083 & 2.24 \\
\hline 17 & Single but living with a partner & 0.411 & 0.191 & 1.51 \\
\hline 18 & Re-married & 0.592 & 0.329 & 1.81 \\
\hline 19 & Divorced, widowed & -0.002 & 0.297 & 1.00 \\
\hline 20 & $\begin{array}{l}\text { Living arrangements } 2001 \\
\text { Baseline: married }\end{array}$ & & & \\
\hline 21 & Single & 1.016 & 0.282 & 2.76 \\
\hline 22 & Single but living with a partner & 0.547 & 0.211 & 1.73 \\
\hline 23 & Re-married & 0.048 & 0.151 & 1.05 \\
\hline 24 & Divorced, widowed & 0.155 & 0.101 & 1.17 \\
\hline 25 & $\begin{array}{l}\text { Economic activity } 1991 \\
\text { Baseline: Economic Inactive }\end{array}$ & & & \\
\hline 26 & Unemployed & 1.252 & 0.244 & 3.50 \\
\hline 27 & Self-employed & 0.955 & 0.200 & 2.60 \\
\hline 28 & Employed & 1.573 & 0.116 & 4.82 \\
\hline 29 & $\begin{array}{l}\text { Economic activity } 2001 \\
\text { Baseline: Economic Inactive }\end{array}$ & & & \\
\hline 30 & Unemployed & 0.348 & 0.276 & 1.42 \\
\hline 31 & Self-employed & 0.185 & 0.173 & 1.20 \\
\hline 32 & Employed & 0.310 & 0.109 & 1.36 \\
\hline 33 & $\begin{array}{l}\text { Social Class } 1991 \\
\text { Baseline - Unskilled }\end{array}$ & & & \\
\hline 34 & I-Professional & 1.625 & 0.322 & 5.08 \\
\hline 35 & II - Intermediate & 1.427 & 0.255 & 4.17 \\
\hline 36 & IIIN - Skilled Non Manual & 1.272 & 0.253 & 3.57 \\
\hline 37 & IIIM - Skilled Manual & 1.221 & 0.285 & 3.39 \\
\hline 38 & IV - Partly Skilled & 0.702 & 0.268 & 2.02 \\
\hline 39 & Other & 0.828 & 0.312 & 2.29 \\
\hline 40 & Has a LLTI 1991 & 1.197 & 0.166 & 3.31 \\
\hline 41 & Has a LLTI 2001 & 0.561 & 0.115 & 1.75 \\
\hline 42 & Does not have siblings 1971 & 0.199 & 0.100 & 1.22 \\
\hline 43 & Constant & -5.717 & 0.293 & 0.00 \\
\hline
\end{tabular}

Italic lines indicate non-significant coefficients at the 0.05 level. Source: ONS Longitudinal Study, Authors' analysis

compared to the mother group ( 30.5 per cent versus 25.2 per cent $)^{12}$ However, compared with mothers, more childless women are in a higher social class than their partner ( 39.0 per cent), while more mothers are in a lower social class than their partner $(40.8 \text { per cent })^{13}$.

\section{Logistic regression}

Partners' marital status, age, education and social class were included in the logistic model identified in section 5.8 and the analysis was re-run using only those women in a partnership in 1991. The model's coefficients are reported in Table 19.

The 1991 living arrangement variable was modifed to reflect the exclusion of women without a partner from the analysis. The new living arrangements variable included a more detailed breakdown of the couple's marital status (see Table 19, rows 7-14).

The logistic regression model confirms many of the results of the univariate analysis on partners' characteristics. Women who have a partner more than five years older than themselves are more likely to be childless. Among women with partners over ten years older, the odds of being childless are more than twice that for women who have a partner of the same age. A smaller, although still statistically significant, coefficient is also found when women are more than five years older than their partner (rows 1-6, Table 19).

Looking at marital status, women in marriages that were not first marriages for both partners were more likely to be childless (rows 7-14, Table 19). The odds were particularly high for those couples where at least one partner was single (never married), with the highest likelihood of childlessness recorded for those single women living with a divorced/ widowed partner followed by couples where both partners were single.

Once a couple's marital status was included, the partner's social class was excluded from the model as it was not statistically significant. This suggests the presence of social class differentials in partnership formation and dissolution.

\section{Conclusions}

This article has investigated the extent to which women's lifelong childlessness is associated with their own socio-economic and other individual characteristics and, where applicable, with the socio-economic characteristics of their partners. The analysis concentrated on a cohort of women born between 1956 and 1961, for which complete fertility histories are now available in the LS.

Quantitative research on childlessness in the UK has previously relied mainly upon the Birth Cohort Studies (BCS). This is the first analysis using the LS to investigate childlessness as a stand-alone topic. Compared to the BCS, the LS does not contain such a wide range of topics, as it is limited to variables collected at census and at registration. However, the BCS covers only selected birth cohorts while the LS is representative of all birth cohorts thus allowing for more detailed analysis of changes in fertility behaviours over time ${ }^{14}$. This analysis can therefore be extended to younger cohorts when the data becomes available. Indeed, it may be interesting to investigate whether the observed socio-economic differentials in childlessness remain similar for more recently born cohorts.

Using the LS, we have been able to produce robust statistical results as the LS is a large-scale nationally representative sample of women and their partners resident in England and Wales. Consequently, we have been able to test some of the hypotheses that have been suggested elsewhere in the literature on a larger sample than has previously been possible. As partnership rates are lower in the childless group, other studies had been limited by small sample sizes when analysing women's partners (Hakim, 2005).

The longitudinal nature of the LS has also allowed us to analyse a wide range of both common and underused variables in relation to childlessness, such as women's socio-economic characteristics at different points in time, including early life-course variables. We have 
provided insight into some of the drivers behind childlessness, and explored in detail who childless women are and how their profile differs from those of women who bear children.

A summary of the main results from the univariate and multivariate logistic regression models shows that, as has been previously suggested by Berrington (2004), the lack of a partner still appears to be one of the main factors associated with childlessness. Single women are the most likely to be childless while married women are least likely to be childless. However, the majority of women who were childless in this sample still lived with a partner, either being married or cohabiting, at some point in time during the course of the study ( 68 per cent). We also found that cohabiting women are less likely than married women to be mothers.

Irrespective of their partnership status, women's own socio-economic characteristics, including economic activity and social class, are significantly associated with childlessness. Where applicable, partners' characteristics, including age and marital status, are also linked to women's childlessness.

However, the models and results presented here do not explain all variation in fertility outcomes between women. To have a greater understanding of why some women remain childless, readers should also refer to the wealth of in-depth analysis that takes account of intentions, opinions, attitudes and values; these topics are not covered in the LS data (see, for example, Fisher (1991), Lisle (1996), McAllister and Clarke (1998)).

\section{Acknowledgements}

Census outputs used here are Crown copyright and are reproduced with the permission of the Controller of HMSO (LS project 20114, paper's clearance number 20114E). The authors alone are responsible for the interpretation of the data. The authors would like to thank ONS colleagues Julie Jefferies from the Fertility Analysis Unit and Dawn Snape from the Micro-Analysis and User Support Unit, who provided helpful comments on an earlier version of this article.

\section{Appendix}

\section{Table A1}

Log-linear saturated model, partners and childlessness

\begin{tabular}{|c|c|c|c|}
\hline Parameter & Reference & Estimate & P-value \\
\hline $\mathrm{P} 01{ }^{*} \mathrm{Cls}$ & No partner 2001, Childless & 0.075 & $<0.0001$ \\
\hline $\mathrm{P} 91{ }^{*} \mathrm{Cls}$ & No partner 1991, Childless & 0.233 & $<0.0001$ \\
\hline $\mathrm{P} 81$ * $\mathrm{Cls}$ & No partner 1981, Childless & 0.370 & $<0.0001$ \\
\hline P01 & No partner 2001 & -0.389 & $<0.0001$ \\
\hline P91 & No partner 1991 & -0.379 & $<0.0001$ \\
\hline P81 & No partner 1981 & 0.322 & $<0.0001$ \\
\hline Cls & Childless & -0.772 & $<0.0001$ \\
\hline$P 01 * P 91$ & No partner 2001, No partner 1991 & 0.513 & $<0.0001$ \\
\hline $\mathrm{P} 01$ *P81 & No partner 2001, No partner 1981 & 0.076 & $<0.0001$ \\
\hline$P 91$ *P81 & No partner 1991, No partner 1981 & 0.261 & $<0.0001$ \\
\hline $\mathrm{P} 81$ *P91 *P01 & $\begin{array}{l}\text { No partner 1981, No partner 1991, } \\
\text { No partner } 2001\end{array}$ & 0.073 & 0.0001 \\
\hline $\mathrm{P} 81{ }^{*} \mathrm{P} 91{ }^{*} \mathrm{Cls}$ & $\begin{array}{l}\text { No partner 1981, No partner 1991, } \\
\text { Childless }\end{array}$ & 0.121 & $<0.0001$ \\
\hline $\mathrm{P} 81{ }^{*} \mathrm{P} 01{ }^{*} \mathrm{Cls}$ & $\begin{array}{l}\text { No partner 1981, No partner 2001, } \\
\text { Childless }\end{array}$ & 0.083 & $<0.0001$ \\
\hline $\mathrm{P} 91$ * $\mathrm{P} 01 * \mathrm{Cls}$ & $\begin{array}{l}\text { No partner 1991, No partner 2001, } \\
\text { Childless }\end{array}$ & 0.016 & 0.392 \\
\hline $\mathrm{P} 81{ }^{*} \mathrm{P} 91{ }^{*} \mathrm{P} 01{ }^{*} \mathrm{Cls}$ & $\begin{array}{l}\text { No partner 1981, No partner 1991, } \\
\text { No partner 1981, Childless }\end{array}$ & 0.057 & 0.003 \\
\hline
\end{tabular}

Note: Bold font highlights the parameters for main association between partner's absence and childlessness

Source: ONS Longitudinal Study, authors' own analysis

\section{Notes}

1 As part of a study on the retention of highly qualified women scientists in science-based employment in England and Wales, Blackwell and Glover (2007) used the LS to show that women who stay in science-based employment have higher rates of non-motherhood than other types of graduate.

2 Involuntary childlessness mainly refers to those individuals who experience fertility problems. The United Nations World Fertility Survey reported that between 2 and 3 per cent of women aged 25-50 are infertile (Vaessen 1984).

3 England and Wales statistics are derived from ONS published figures of average first births per woman estimated using the true birth order process. See FM1 Birth Statistics, table 10.3 and section 2.9 .

4 Both LS and England and Wales figures refer to births up to December 2005. Women who have not had any live- or stillbirth are classified as childless in the LS, while England and Wales figures take into account only live births. England and Wales figures are rounded whereas figures from the LS are not rounded.

5 As the LS only includes information on partnership status of its members at census, this figures underestimates the real number of women living with a partner/husband during the entire 1981-2001 period. Indeed, unions which started and ended between two consecutive censuses are missed.

6 LS members' partners are not linked through time. Therefore it is not possible to say whether a woman is living with the same or a different partner at different censuses.

7 The Office for National Statistics (ONS) regularly publishes labour market statistics by age and gender, see Labour Market Trends (up to 2006) and Economic and Labour Market Review (2006 onwards)

8 The LS captures only migration from one census to the next, that is, over a ten year period.

9 The sample excludes all immigrants in the UK, unless they immigrated during childhood. See section 4

10 See note 5

11 The 1991 Census only asked respondents to list their qualifications attained after the age of 18 . Any qualification attained before that age (that is, GCSE or A-level equivalent) would not be listed.

12 These percentages are based on those couple where both partners had a social class value. Only 3 per cent of partners are economically inactive

13 Note that women with missing social class have been excluded from this part of the analysis.

14 Given that this study focuses on lifelong fertility outcomes, it focuses on a five year birth cohort from the LS.

\section{References}

Blackwell L and Glover J (2007) Women's Scientific Employment and Family Formation: A Longitudinal Perspective, Gender, Work and Organization, 15, 6, 579-599.

Berrington A (2004) 'Perpetual postponers? Women's, men's and couple's fertility intentions and subsequent fertility behaviour', Population Trends 117, 9-117.

Castles F (2003) 'The world turned upside down: below replacement fertility, changing preferences and family friendly policy in 21 OECD Countries', Journal of European Social Policy 13(3), 209-227.

Coleman D (1996) 'New patterns and trends in European fertility: international and sub-national comparisons', in Coleman D (ed.), Europe's Population in 1990, Oxford University Press, Oxford, 1-61.

De Cooman E, Ermisch J and Joshi H (1987) 'The next birth and the labour market: a dynamic model of births in England and Wales', Population Studies 41(2), 237-268.

Fisher B (1991) 'Affirming social value: women without children', in Maines, D. R. (ed.), Social Organization and Social Process: Essays in Honour of Anselm Strauss, A. de Gruyter, New York. 
Hakim C (2003) 'A new approach to explaining fertility patterns: preference theory', Population and Development Review 29, 349-74.

Hakim C (2005) Childlessness in Europe: research report to the Economic and Social Research Council (10/03/2005), available at: www.esrcsocietytoday.ac.uk/ESRCInfoCentre/Plain_English_ Summaries/LLH/lifecourse/index498.aspx?ComponentId=9309\& SourcePageId $=11751$

Jefferies J (2008) 'Fertility assumptions for the 2006-based national population projections', Population Trends 131, 19-27.

Joshi H (2002) 'Production, reproduction and education: women, children and work in contemporary Britain', Population and Development Review 28(3), 445-474.

Kiernan K (1989) 'Who remains childless?', Journal of Biosocial Science 21, 387-398.

Kneale D and Joshi H (2008) 'Postponement and childlessness Evidence from two British cohorts', Demographic Research 19, 1935-1968.

Lisle L (1999) Without Child, Routledge, New York.

McAllister F and Clarke L (1998) Choosing Childlessness, Family Policy Studies Centre, London.

McDonald P (2000) 'Gender equity in theories of fertility transition', Population and Development Review 26(3), 427-439.

Murphy M (2008) 'Estimates of childlessness in Britain from the mid 19th Century', Paper presented at the British Society of Population Studies Annual Conference, 10-12 September 2008

Office for National Statistics, 2006, Births Statistics 2005, Series FM1, No. 34

Office for National Statistics, 2008, Births Statistics 2007, Series FM1, No. 36
Office for National Statistics, 2004, Focus on Gender.

Parr N J (2005) 'Family background, schooling and childlessness in Australia', Journal of Biosocial Science 37, 229-243

Pearce D, Cantisani G and Laihonen A (1999) 'Changes in fertility and family sizes in Europe', Population Trends 95, 33-40.

Plotnick R D and Evans D J (2008) Childlessness and the Economic Well being of Elders, Center for Studies in Demography and Ecology, University of Washington.

Rendall M S and Smallwood S (2003) 'Higher qualifications, first-birth timing, and further childbearing in England and Wales', Population Trends 111, 18-26.

Simpson R (2006) Delayed childbearing in Britain: the 1958 and 1970 Cohort Studies Compared, Centre for Research on Families and Relationships, Edinburgh.

Sobotka T (2004) Postponement of childbearing and low fertility in Europe, Dutch University Press.

Vaessen M (1984) Childlessness and Infecundity, World Fertility Studies, 31, Voorburg - International Statistical Institute.

Veevers J E (1980) Childless by Choice, Butterworths, Toronto.

\section{Footnote}

This research was awarded first prize in the Neville Butler Memorial Prize. The Neville Butler Memorial prize is co-funded by ESRC and Longview and has been set up to reward and encourage publicly relevant new work grounded in empirical analysis of longitudinal data by early career researchers. 